\title{
Histochemical study of asbestos fibre coating in experimental carrageenin granulomas
}

\author{
M. GOVERNA and C. ROSANDA VADALÀ \\ Laboratory of Experimental Pathology, Institute of Industrial Medicine, \\ University of Genoa, I-16132 Genoa, Italy
}

\begin{abstract}
Governa, M., and Rosanda Vadalà, C. (1973). British Journal of Industrial Medicine, 30, 248-252. Histochemical study of asbestos fibre coating in experimental carrageenin granulomas. To study the composition of asbestos body coating, asbestos particles present in experimental carrageenin granulomas were tested histochemically for mucopolysaccharides, ferric and ferrous iron, haemoglobin, and haematoidin. The stains were applied on microscopical sections both untreated and treated with iron-extracting solutions and/or enzymes. The results indicate that asbestos is rapidly coated with haematoidin, ferric iron, and hyaluronic acid.
\end{abstract}

The asbestos body has been known for a long time to be coated by iron and proteins (Gloyne, 1932; Beger, 1933; Sundius and Bygdén, 1937). Moreover, recent histochemical observations (Governa and Rosanda, 1972) indicate that hyaluronic acid is present in the internal layers of the bodies, while ferric iron is present in the external ones.

Nevertheless asbestos bodies treated first with iron-extracting solutions and then with testicular hyaluronidase were still coated with a material which did not react with toluidine blue at a pH range of 2.0 to 3.0 (Governa and Rosanda, 1972).

The composition of the asbestos body coating might be made clear by studying the substances surrounding asbestos just introduced into tissues. We undertook, therefore, a histological study of granulomas due to carrageenin, into which asbestos fibres had been introduced.

In order to verify the view (Davis, 1970a and b) that asbestos fibres were first coated with acid mucopolysaccharides which then became impregnated with iron, the relationship between asbestos fibres and the mucopolysaccharides of the connective ground substance has been especially examined. The carrageenin granuloma was chosen as it is rich in interstitial mucopolysaccharides (Jackson, 1956; Williams, 1957; Prodi and Romeo, 1967).
Other substances have also been tested to see whether they are present on asbestos fibres.

\section{Materials}

Asbestos dust

P 600 , a commercially available asbestos dust (Società Amiantifera Balangero, Balangero, Torino, Italy) was used. This contains chrysotile fibres, 0.01 to $0.3 \mathrm{~mm}$ long and 0.001 to $0.02 \mathrm{~mm}$ in diameter.

\section{Carrageenin}

Irish Moss (Nutritional Biochemicals Corporation, Cleveland, Ohio, 44128, USA, cod. 4565) was used.

\section{Animals}

Guinea-pigs of both sexes were used throughout; their weights ranged from 600 to $800 \mathrm{~g}$.

\section{Methods}

Production of carrageenin granulomas and preparation of tissues and sections

Under open ether anaesthesia each animal was injected subcutaneously on both sides of the lower abdominal wall, on the right with $2 \cdot \mathrm{ml}$ of a $1 \%$ solution of carrageenin in $0.9 \% \mathrm{NaCl}$ and on the left with $2 \mathrm{ml}$ of the same solution in which $10 \mathrm{mg}$ of asbestos had been suspended. Three animals were killed every other day 
from the third until the twenty-first day after the injections, and whole-thickness slices of the abdominal wall were taken for histological sectioning. The tissues were fixed in $10 \%$ formol saline, processed through ethanol and benzene, and embedded in paraffin. A series of representative 5 micron sections was cut.

Histochemical methods

The following staining techniques were applied.

Iron techniques Perls and Turnbull reactions were used to demonstrate ferric and ferrous iron.

Mucopolysaccharide techniques Periodic acid Schiff (PAS); toluidine blue at $\mathrm{pH}$ range $1-3$; fresh $1 \%$ Alcian blue $8 \mathrm{GX}$ in $3 \%$ acetic acid pH 2.4 with the addition of $0 \cdot 1,0 \cdot 2,0 \cdot 5,0 \cdot 6,0 \cdot 8$, and $1 \cdot 0 \mathrm{~mol} / 1 \mathrm{MgCl}_{2}$.

Haemoglobin techniques The Dunn-Thompson and Okajima methods were used.

Haematoidin techniques The azocoupling reaction at pH 2.3 with diazotate safranin $\mathrm{O}$ at a concentration of $1 \mathrm{mmol}$ for haematoidin, according to Lillie and Pizzolato (1969a), was carried out. The acetic haematoxylin staining after mordanting with $\mathrm{CrO}_{3}$ (Lillie and Pizzolato, 1969b) was also used; but more consistent results were obtained with the azocoupling reaction, background staining being very faint or absent at a $1 \mathrm{mmol}$ concentration of safranin $\mathrm{O}$ at $\mathrm{pH} 2 \cdot 3$.

Additional procedures were carried out to evaluate further the histochemical properties of the tissues.

Iron extraction was performed by means of an overnight (about 14 hours) bath in $5 \%$ oxalic acid or a fiveminute bath in $1 \%$ sodium dithionite in $0.1 \mathrm{~mol} / 1$ acetate buffer, pH 4.5 (Lillie, Geer, and Gutiérrez, 1963).

Enzymatic digestion with testicular hyaluronidase (Jalovis, Vister Casatenovo Brianza, Como, Italy), 15 units $/ \mathrm{ml}$ in $0.1 \mathrm{~mol} / 1 \mathrm{Na}-\mathrm{K}$ phosphate buffer at $\mathrm{pH} 6.0$ for 48 hours, at $37^{\circ} \mathrm{C}$ was performed.

Methylation $(0.1 \mathrm{~N}$ hydrochloric acid in absolute methanol for 2 hours at $60^{\circ} \mathrm{C}$ ) was carried out, sometimes followed by saponification ( $1 \%$ potassium hydroxide in $70 \%$ ethanol for 20 minutes at room temperature).

Enzymatic digestion with trypsin was performed using $0.1 \%$ trypsin (Code 8214-53, Merck AG, Darmstadt, Germany) in $0.01 \mathrm{~mol} / 1$ phosphate buffer at pH 7.6 with $0.4 \% \mathrm{NaCl}$ and $0.1 \% \mathrm{NaF}$ for 30 to 180 minutes at $37^{\circ} \mathrm{C}$.

\section{Controls}

The validity of the histochemical methods used for mucopolysaccharides, i.e., PAS, toluidine blue, and Alcian blue, on sections processed through oxalic acid or sodium dithionite had already been assessed (Governa and Rosanda, 1972), while those for haemoglobin and haematoidin are now described. The erythrocytes present in the tissues examined were used as a source of haemoglobin. They still showed a haemoglobin positive reaction after iron extraction. As a source of haematoidin, microscopical sections of human haemorrhagic areas containing extracellular yellowish-brown rhombic crystals or amorphous granules not reacting to ferrocyanide were used. These granules also appeared to be haematoidin positive after iron extraction. In fact, Lillie and Pizzolato (1969b) had already observed that pretreatment with dithionite did not affect the ability of haematoidin to stain with acetic haematoxylin after $\mathrm{CrO}_{3}$ oxidation.

\section{Results}

\section{Reaction to carrageenin}

On the third day after injection a very large exudate was observed. There were many polymorph and mononuclear leucocytes as well as red blood cells in the serous fluid. On the fifth day new granulation tissue was seen. It was very rich in cells and ground substance. Numerous macrophages appeared intimately mixed with fibroblasts. On the thirteenth day the highly cellularized tissue contained both macrophages and fibroblasts. There was a small amount of ground substance, and a network of fine reticulin fibrils surrounded the cells. On the fifteenth day thicker collagen fibres appeared in the peripheral zone of the granuloma.

On the third day masses of carrageenin lay free among the cells in the fluid exudate; only a small part was ingested by mononuclear cells. On the fifth day carrageenin was still abundant in the connective ground substance but by the seventh to ninth days the amount was less, and by the eleventh day it had disappeared.

\section{Behaviour of asbestos in fluid exudate}

On the third day after injection asbestos bundles lay free among the leucocytes and erythrocytes. There were also a few isolated fibres, free or phagocytosed by mononuclear cells. The asbestos bundles and fibres were Turnbull, Perls, Dunn-Thompson, and Okajima negative; they were unstained using both techniques for haematoidin. Indeed, most of the asbestos was unstained after PAS and toluidine blue (Fig. 5); only very few asbestos bundles, immersed in large masses of carrageenin, exhibited the same PAS positivity and metachromatic staining with toluidine blue as carrageenin itself. This capacity to be metachromatically stained with toluidine blue was also retained after treatment with testicular hyaluronidase, whereas it was lost after methylation and saponification.

\section{Behaviour of asbestos in new granulation tissue} From the seventh to the fifteenth days many bundles and isolated asbestos fibres were observed in the ground substances of the connective tissue. From that time on (day 17, 19, and 21) most asbestos fibres were surrounded by large macrophages with several nuclei, and many dust particles appeared to have been phagocytosed.

Asbestos fibres in new granulation tissue have been specially studied with histochemical methods. Serial microscopical sections containing asbestos 
TABLE

Histochemical Properties of Asbestos Fibres in Carrageenin Granuloma in Earliest Stages OF DEVELOPMENT

\begin{tabular}{|c|c|c|c|c|c|c|c|c|c|}
\hline & Perls & Turnbull & $P A S$ & $\begin{array}{c}\text { Toluidine } \\
\text { blue }\end{array}$ & $\begin{array}{c}\text { Alcian } \\
\text { blue }\end{array}$ & $\begin{array}{c}\text { Dunn- } \\
\text { Thompson }\end{array}$ & Okajima & $\begin{array}{c}\text { Diazotate } \\
\text { safranin } O\end{array}$ & $\begin{array}{c}\text { Acetic } \\
\text { haematoxylin } \\
\text { after } \mathrm{CrO}_{3}\end{array}$ \\
\hline $\begin{array}{l}\text { Untreated sections ... } \\
\text { After iron extraction } \\
\text { After testicular hyaluronidase } \\
\text { After trypsin .. } . \\
\text { After iron extraction and tes- } \\
\text { ticular hyaluronidase } . . \\
\text { After iron extraction, testicu- } \\
\text { lar hyaluronidase, and } \\
\text { trypsin .. .. }\end{array}$ & $\begin{array}{l} \pm \\
- \\
\pm \\
\pm \\
-\end{array}$ & $\begin{array}{l}\bar{z} \\
\bar{z} \\
-\end{array}$ & $\begin{array}{l}\bar{z} \\
\bar{z} \\
-\end{array}$ & $\begin{array}{l} \pm \mathbf{M} \\
\pm \mathbf{M} \\
\pm \mathbf{M} \\
-\end{array}$ & $\begin{array}{l} \pm * \\
\text { nd } \\
\text { nd } \\
\text { nd } \\
\text { nd } \\
\text { nd }\end{array}$ & $\begin{array}{l}- \\
\overline{-} \\
- \\
-\end{array}$ & $\begin{array}{l}\overline{-} \\
\overline{-} \\
\overline{-}\end{array}$ & $\begin{array}{l} \pm \\
\pm \\
\pm \\
\pm \\
\pm\end{array}$ & $\begin{array}{l} \pm \\
\pm \\
\pm \\
\pm \\
\pm\end{array}$ \\
\hline
\end{tabular}

+ positive reaction; - negative reaction; \pm some asbestos fibres stained; $M$ metachromasia; nd $=$ not done; $-=$ positive reaction with $0.1,0.2$, and $0.5 \mathrm{~mol} / 1 ;{ }^{*}$ negative reaction with $0.6,0.8$, and $1.0 \mathrm{~mol} / 1 \mathrm{MgCl}_{2}$

were tested, a first group processed through ironextracting solution and/or enzymatic digestion and a second unprocessed. The results are summarized in the Table and described below.

No difference was observed between the asbestos outside and inside the cells.

As it is much more difficult to find in tissues asbestos fibres which have not reacted to the staining processes employed we can only say that the amount of stained asbestos was always very small compared with that which did not react.

As regards the reactivity of asbestos in the untreated sections, the fibres metachromatically positive to toluidine blue (Figs 4 and 6) or Prussian blue (Figs. 2 and 8 ) were more numerous than the ones which showed a positive red-purple reaction with diazotate safranin $\mathrm{O}$ (Figs 3 and 7) or a positive violet reaction with acetic haematoxylin after $\mathrm{CrO}_{3}$. After toluidine blue or Prussian blue treatment the positive asbestos fibres appeared to be stained differently. Some were uniformly stained, whereas others were mottled. In serial microscopical sections the same bundles of asbestos fibres which were metachromatic with toluidine blue were also observed to be Perls positive (compare Figs 4 and 6 with Figs 2 and 8). These findings have been confirmed by applying Perls stain on sections already stained with toluidine blue. Asbestos fibres in which Prussian blue positive areas appeared to be present have been observed over areas metachromatically stained with toluidine blue (Fig. 1).

The asbestos fibres which showed a positive redpurple reaction to diazotate safranin $O$ were also positive to Perls stain and metachromatic toluidine blue. This was observed by applying these stains on serial sections. Compare Fig. 3, in which the bundles of asbestos fibres are stained with diazotate safranin
O, with Figs 2 and 4, in which the same bundles are stained with Prussian blue and toluidine blue respectively. The same results were obtained by applying Perls stain to sections already treated with diazotate safranin $\mathrm{O}$ : the haematoidin-positive asbestos fibres changed from red-purple to violet. The toluidine blue metachromasia was readily abolished by methylation and restored by saponification.

Some asbestos fibres were positive with Alcian blue staining at $0 \cdot 1,0.2$, and $0.5 \mathrm{~mol} / 1 \mathrm{MgCl}_{2}$ but were negative at $0 \cdot 6,0 \cdot 8$, and $1.0 \mathrm{~mol} / 1 \mathrm{MgCl}_{2}$.

As regards the reactivity of asbestos in sections treated with iron-extracting solutions and testicular hyaluronidase the number of haematoidin-positive bundles and fibres was higher than in the sections untreated or treated with iron-extracting solution, testicular hyaluronidase, and trypsin only.

\section{Discussion}

This experiment was undertaken to test whether asbestos fibres placed in connective tissue are coated with acid mucopolysaccharides and/or iron and whether there is any relationship between the acid mucopolysaccharides and the presence of iron.

Connective tissue in the earliest stages of development of carrageenin granuloma was chosen as it is very rich in mucopolysaccharides.

Stains for acid mucopolysaccharides were negative in both asbestos fibres and connective tissue during the polymorphonuclear leucocyte response. Part of the asbestos became metachromatic to toluidine blue during the formation of new connective tissue in which the mucopolysaccharide stain was also strongly positive.

Metachromatic reaction of asbestos fibres was not 
FIG. 1

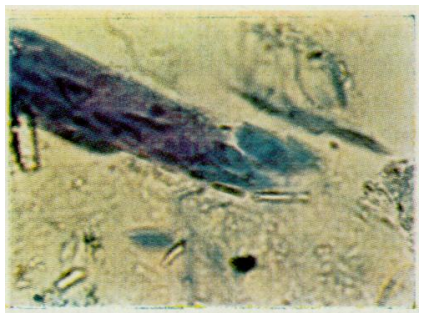

FIG. 3

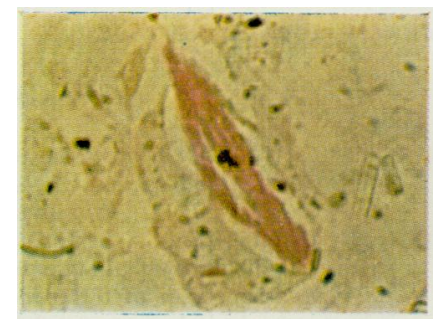

FIG. 5

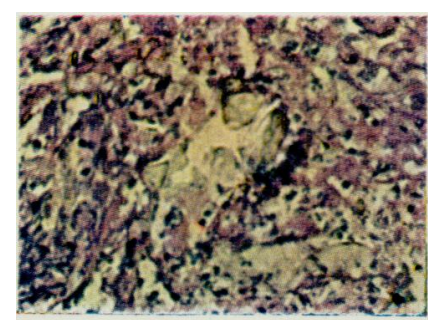

FIG. 7

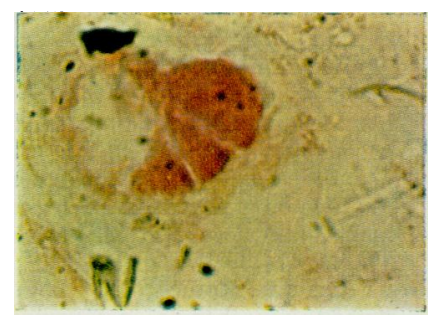

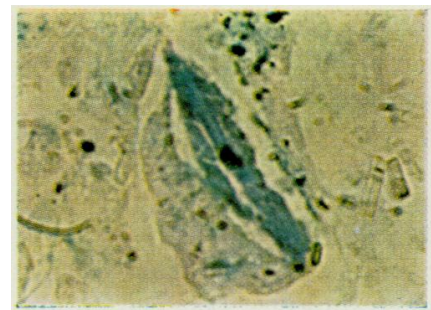

FIG. 2

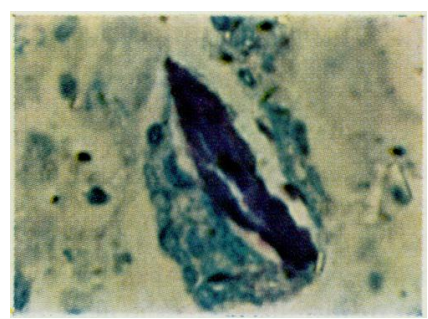

FIG. 4

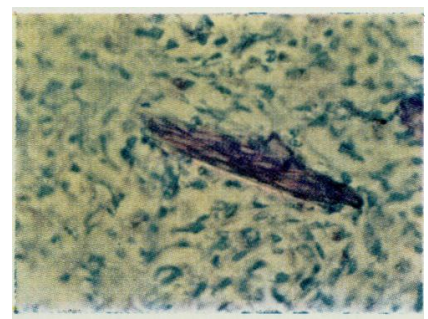

FIG. 6

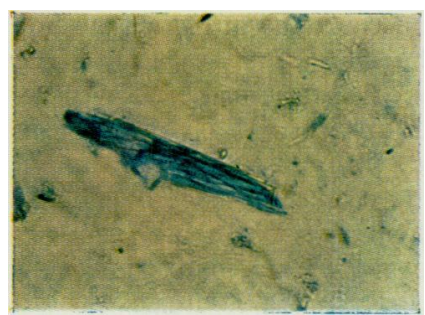

FIG. 8
FIG. 1. Subcutaneous tissues of guinea-pig abdominal wall 11 days after injection of carrageenin and asbestos. Double staining, first with toluidine blue at pH 3 and then with Prussian blue. Asbestos bundles show Prussian blue positive areas over areas metachromatically stained with toluidine blue. Original magnification $\times 1250$.

FIG. 2. The same field as in Fig. 4. Asbestos bundles show a positive reaction to Prussian blue. Original magnification $\times 1250$.

FIG. 3. The same field as in Figs 2 and 4. Diazotate safranin $\mathrm{O}$ at $\mathrm{pH} 2 \cdot 3$. Asbestos bundles show a weak positive red-purple reaction. Original magnification $\times$ 1250.

FIG. 4. Subcutaneous tissues of guinea-pig abdominal wall 19 days after injection of carrageenin and asbestos. Toluidine blue at pH3. Asbestos bundles phagocytosed by a macrophage show metachromatic staining of reddishviolet colour. Original magnification $\times 1250$.
FIG. 5. Subcutaneous tissues of guinea-pig abdominal wall three days after injection of carrageenin and asbestos. Toluidine blue at $\mathrm{pH} 3$. In middle of picture asbestos bundles appear unstained among fluid exudate. Original magnification $\times 500$.

FIG. 6. Subcutaneous tissues of guinea-pig abdominal wall nine days after injection of carrageenin and asbestos. Toluidine blue at pH 3. Asbestos bundles in new granulation tissue show metachromatic staining of reddishviolet colour. Original magnification $\times 500$.

FIG. 7. Subcutaneous tissues of guinea-pig abdominal wall 13 days after injection of carrageenin and asbestos. Diazotate safranin $\mathrm{O}$ at $\mathrm{pH} 2 \cdot 3$. Asbestos bundles show a positive red-purple reaction. Original magnification $\times$ 1250.

FIG. 8. The same field as in Fig. 6. Asbestos bundles show a positive reaction to Prussian blue. Original magnification $\times 500$. 
seen in sections exposed to testicular hyaluronidase or treated with methanol- $\mathrm{HCl}$; after methylation metachromasia was restored by saponification.

Some asbestos fibres were positive to Alcian blue at low concentrations of magnesium chloride $(0 \cdot 1$ to $0.5 \mathrm{~mol} / \mathrm{l})$ but became negative at higher concentrations $(0.6$ to $1.0 \mathrm{~mol} / \mathrm{l})$.

The metachromatic extracellular connective substances of carrageenin granuloma behaved in the same way after treatment with hyaluronidase or methanol, while the metachromasia of carrageenin was not affected by these treatments.

Thus the toluidine blue metachromasia which appeared on some asbestos fibres seems to be due to the presence of acid mucopolysaccharides and especially hyaluronic acid.

Some of the asbestos fibres were also Perls positive. There was no reaction when the sections were exposed to sodium dithionite or oxalic acid, so that the Prussian blue which was observed on the asbestos fibres seems to have been due to the presence of ferric iron.

Finally, some of the asbestos fibres were haematoidin-positive, appearing red-purple after staining with diazotate safranin $\mathbf{O}$. The reaction was similar to that of the control haematoidin. Staining of background tissue proteins was either absent or very faint. There was a positive reaction when the sections were exposed to tryptic digestion to avoid possible interference by proteins. The histochemical method used is able to demonstrate the presence of bile pigments as well as haematoidin, the latter being very similar to or identical with bilirubin. Nevertheless, the positive reaction which was observed in asbestos fibres stained with diazotate safranin $O$ seems to have been due to the presence of haematoidin rather than bile pigments. In fact asbestos fibres introduced into the tissues had come into contact with extensive haemorrhagic areas.

It was noted that the asbestos fibres which were positive to haematoidin also showed a toluidine blue metachromasia and were positive to Perls stain. This could be explained in two ways: either there is a mixture of ferric iron, hyaluronic acid, and haematoidin on the asbestos fibres, or there are distinct layers, the outer ones so thin that the interior ones could still react positively. The experiments carried out with iron-removing solutions and tes- ticular hyaluronidase do not seem to have solved the question of the relationship of ferric iron to hyaluronic acid. Instead they seem to suggest that the interior layer consists of haematoidin. In fact the presence of ferric iron and hyaluronic acid masked the reactivity of some asbestos fibres tested with diazotate safranin $\mathbf{O}$.

Asbestos introduced into tissue seems to be quickly coated with haematoidin and hyaluronic acid; ferric iron particles have also been observed closely apposed to asbestos.

\section{References}

Beger, P. J. (1933). Über die Asbestosiskörperchen. Virchows Archiv für pathologische Anatomie und Physiologie und für klinische Medizin, 290, 280-353.

Davis, J. M. G. (1970a). Asbestos dust as a nucleation center in the calcification of old fibrous tissue lesions, and the possible association of this process to the formation of asbestos bodies. Experimental and Molecular Pathology, 12, 133-147.

(1970b). Further observations on the ultrastructure and chemistry of the formation of asbestos bodies. Experimental and Molecular Pathology, 13, 346-358.

Gloyne, S. R. (1932). The asbestosis body. Lancet, 1, 13511355.

Governa, M., and Rosanda, C. (1972). A histochemical study of the asbestos body coating. British Journal of Industrial Medicine, 29, 154-159.

Jackson, D. S. (1956). The stimulation of connective tissue formation by carrageenin. Biochemical Journal, 62, 25P.

Lillie, R. D., Geer, J. C., and Gutiérrez, A. (1963). The removal of histochemically demonstrable iron from tissue sections by brief exposure to sodium dithionite solution. Journal of Histochemistry and Cytochemistry, 11, 662-664.

reactions of the pigments of obstructive icterus and of hematoidin. I. Diazonium salts used. Journal of Histochemistry and Cytochemistry, 17, 738-748.

- , and _- (1969b). Histochemical metal uptake reactions of the bile pigments of obstructive icterus and of hematoidin. Journal of Histochemistry and Cytochemistry, 17, 467-474.

Prodi, G., and Romeo, G. (1967). The evolution of acid mucopolysaccharides in carrageenin granulomata. British Journal of Experimental Pathology, 48, 40-44.

Sundius, N., and Bygdén. (1937). Der Staubinhalt einer Asbestosislunge und die Beschaffenheit der sogenannten Asbestosiskörperchen. Archiv für Gewerbepathologie und Gewerbehygiene, 8, 26-70.

Williams, G. (1957). A histological study of the connectivetissue reaction to carrageenin. Journal of Pathology and Bacteriology, 73, 557-563.

Received for publication September 11, 1972. Accepted for publication November 16, 1972. 
2. Duration (days) $=\frac{\text { No. of days' absence in year }}{\text { Population (person years) }}$

It is also often useful to use other rates, but these are of less importance and should not replace 1 and 2 above. These may include:

3. Point prevalence $=$

No. of persons absent on day $\%$

Population employed on that day

4. Frequency (persons) $=$

No. of persons having one or more spells in year $\%$

Population (person years)

5. Lost time $=$

No. of working days or hours lost in a period \%

Potential working days or hours in the same time

7. Although for routine purposes rates are usually calculated for the main groups in occupation, sex, and age, there may be advantage in studying other rates, e.g., injuries, operations, respiratory, digestive, or cases receiving compensation, etc.

\section{Proposal for action}

The sub-committee recommends that a voluntary system of recording of sickness absence on the lines indicated by the sub-committee should be tried out in a few countries to see whether it is possible to establish some degree of international comparison.

Occupational physicians who would be prepared to help are invited to submit annual rates of absence for their factories to a national co-ordinator. He will keep the chairman of the sub-committee informed of the number of organizations from which he is receiving such information. It may then be possible to provide some international comparison of absence for the 18th International Congress on Occupational Health.

Meeting in San Paulo, Brazil, 14 September 1972

Members of the Sub-committee on Absenteeism:

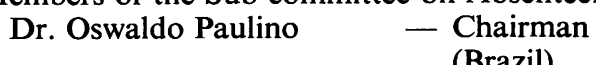

Dr. Arthur Ernesto Moniz - Secretary (Portugal)

Dr. Peter J. Taylor - Member (UK)

Dr. Diogo Pupo Nogueira - Member (Brazil)

Dr. Pedro Sangro - Member (Spain)

Dr. José H. Molteni - Member (Argentina)

\section{References}

London Transport Executive (1956). Health in Industry. A Contribution to the Study of Sickness Absence. Experience in London Transport. Butterworth, London.

World Health Organization (1967). Manual of the International Statistical Classification of Diseases, Injuries, and Causes of Death. 8th Revision, 1965. W.H.O., Geneva.

\section{CORRECTION}

'Histochemical study of asbestos fibre coating in experimental carrageenin granulomas' by $\mathbf{M}$. Governa and C. Rosanda Vadalà, vol. 30, pp. 248-252.

The footnote to the Table on p. 250 should read: + positive reaction; - negative reaction; \pm some asbestos fibres stained; $M=$ metachromasia; $n d=$ not done; ${ }^{*}$ positive reaction with $0.1,0.2$, and 0.5 $\mathrm{mol} / \mathrm{l}$ but negative reaction with $0 \cdot 6,0 \cdot 8$, and $1.0 \mathrm{~mol} / \mathrm{l}$ $\mathrm{MgCl}_{2}$.

The following acknowledgement was omitted:

This study was supported by a grant from the Quebec Asbestos Mining Association. 